Adrian Pablé

\title{
An integrational response to Searlean realism, or how language does not relate to consciousness
}

\begin{abstract}
The relationship between language and a science of consciousness is rarely treated as crucial for the field's metatheory (i.e., its underlying philosophical assumptions about the role and nature of language). John Searle is among those thinkers who has given language due attention as part of his realist philosophy, and semantic questions turn out to be in the forefront of his plea for a scientific approach to the phenomenon of consciousness. This paper will consider Searle's philosophy of language in the light of an integrational theory of communication (Harris 1981, 1996, 1998). It is argued here that Searlean realism is grounded in a "reocentric" conception of the world, which (wrongly) assumes an isomorphic relation between language and what language refers to.
\end{abstract}

Keywords: integrationism; Roy Harris; John Searle; science of consciousness; realism; reocentrism

Adrian Pablé: University of Hong Kong. E-mail: apable@hku.hk

\section{Introduction}

This paper looks at John Searle's philosophical position, termed biological naturalism, as discussed in his two books Mind, Language, and Society (Searle 1998) and Language and Consciousness (Searle 2002): it does so from the vantage point of integrationism, as outlined by its founder Roy Harris (e.g., Harris 1996, 1998, 2009b). In some way, this paper continues the integrational critique of Searle's philosophy (of language) undertaken by Nigel Love in his article Searle on Language (Love 1999), which was based on three works by Searle published prior to 1998. ${ }^{1}$ The present article is intended as a response to Searle's claim that consciousness is a purely biological problem, as well as a critical reflection on how

1 Other discussions of Searlean linguistics by integrationists can be found in Harris (1987: 148-152; 1996: 147-151; 231-232) and Toolan (1996: 25-37). 
Searle instrumentalizes language in order to support his views of respectively external realism and the correspondence theory of truth. It is argued here that embracing the latter two views leads to misconceived assumptions about how language, consciousness, and science relate to reality, and hence to upholding the notion that objective science can explore the realm of the ontologically subjective. The integrational account of reality and truth also provides convincing arguments against materialism - as well as its opposing counterpart: (Cartesian) dualism. Both approaches, in fact, fall prey to what integrationists refer to as the "Language Myth" (e.g., Harris 1981, 2004a), i.e., the theses that languages are fixed codes and that verbal communication involves thought-transference from one mind to another. I shall sustain my claim that a reocentric approach to semantics (as advocated as part of Searle's biological naturalism) is untenable by discussing both personal communicational encounters with locals in Hong Kong (where I currently reside), and imagined (but realistic) situations involving the verbalization of conscious experience. In light of Roy Harris' appeal for layorientedness, it is my contention that scientific accounts of what is going on in person A's mind are not to be valued more highly - ontologically and epistemologically speaking - than $A$ 's own (non-scientific) insights: in fact, lay people are themselves psychologists and linguists whenever they reflect on (and talk about) their own (and other people's) experiences.

\section{Searle's vision of a science of consciousness}

For the purpose of the present paper, it is interesting to consider how epistemic objectivity, ontological subjectivity, and language are claimed by the Searlean realist to interrelate. The phenomenon of consciousness, in fact, has attracted a lot of interest in scientific circles lately, in particular within the neurosciences, and has been "rehabilitated as one of the essential topics of psychological theory and philosophy of mind" (Harris 2008: 85). Consciousness, with its subjective mode of existence, is now the object of study of scientific disciplines that traditionally were concerned with material reality, the ontologically objective. John Searle has been a fervent advocate of treating consciousness as a purely biological - but at the same time a special biological - phenomenon, namely, one involving lower-level neuronal processes in the brain, which have a third-person ontology, causing higher-level conscious states and processes, which have a firstperson ontology; by doing so, according to Searle, one leaves behind once and for all the untenable positions of dualism and materialism, which have kept philosophers tightly in the grip of the "metaphysical mind-body problem" (e.g., Searle 1998: 39-57; Searle 2002: 46). By rejecting the Cartesian idea that the conscious 
mind is a separate substance from the brain, and espousing a position according to which the mind is itself a higher-level feature of the brain, it should in principle be possible for a science of consciousness, as conceived by Searle, to produce an "artificial brain [capable of] duplicat[ing] the actual causes of human and animal brains to produce inner, qualitative, subjective states of consciousness" (Searle 1998: 53):

My main message is that we need to take consciousness seriously as a biological phenomenon. Conscious states are caused by neuronal processes, they are realized in neuronal systems and they are intrinsically inner, subjective states of awareness or sentience. We want to know how they are caused by, and realized in, the brain. Perhaps they can also be caused by some sort of chemistry different from brains altogether, but until we know how brains do it we are not likely to be able to produce it artificially in other chemical systems. (Searle 2002: 35)

This, in turn, means that a science of consciousness must ultimately be in a position to deal with types of conscious experience, i.e., underlying typologies of subjective conscious states having a third-person ontology. What it feels like to be drinking water when one is thirsty, therefore, may well be a subjective experience, but there must be a distinctive feel to it, chemically speaking, which is common to each and every actual instance. ${ }^{2}$ In fact, Searle himself (2002: 40) concedes that different "token experiences" may be "qualitatively identical," i.e., they "all exemplify the same type."

Searle's approach to consciousness as a real phenomenon is inextricably bound to a specific doctrine of semantics termed reocentrism (Harris 2004b: 3-8): this view holds that lexical definitions (what the word consciousness means) hold the key to real definitions (what consciousness is). Searle (2002: 38) is content to take "a definition in common-sense terms" as the starting-point for an investigation of consciousness, which will eventually be complemented by a "precise scientific definition" typically available as the result of a scientific inquiry. His common-sense definition of consciousness is as follows:

Consciousness consists of inner, qualitative, subjective states and processes of sentience and awareness. Consciousness, so defined, begins when we wake in the morning from a dreamless sleep and continues until we fall asleep again, die, go into a coma, or otherwise become "unconscious." It includes all of the enormous variety of the awareness that we think of as characteristic of our waking life. It includes everything from feeling a pain, to perceiving objects visually, to states of anxiety and depression, to working out crossword puzzles, playing chess, trying to remember your aunt's phone number, arguing about poli-

2 Concerning an integrational perspective of the so-called "qualia" (and the "what-it-is-like" idiom), see, e.g., Harris (2008: 86-88). 
tics, or to just wishing you were somewhere else. Dreams on this definition are a form of consciousness, though of course they are in many respects quite different from waking consciousness. (Searle 2002: 38)

Searle does not claim that this is how the word consciousness is used universally by "commonsensical" people. As he concedes: "It is, of course, open to anyone to use any word anyway he likes" (Searle 2002: 39), but adds that "we can always redefine consciousness as a technical term." Searle then goes on to state that there is "something" - "a genuine phenomenon of consciousness in the ordinary sense" - "however we choose to name it." Searle, therefore, is interested in identifying that very phenomenon for which ordinary language provides the label consciousness, but the label itself is not the target of his investigation. However, it soon becomes evident that Searle's realism cannot be divorced from his reocentric view of language: in fact, as he makes clear, the prerequisite for a scientific - and hence a true - description of consciousness requires "a conceptual revision" (1998: 69); in other words, understanding the real nature of consciousness is first and foremost a question of getting one's semantics right: "The problem is not with our access to the facts. The problem is with the set of categories that we have inherited for describing the facts" (Searle 1998: 69). Once this set of categories is abandoned, it becomes possible, in Searle's words, to "see that consciousness is a biological phenomenon like any other," and, as a consequence, "then we can see that, of course, in some sense it is completely 'material'" (Searle 1998: 69, emphasis added). By "shifting the categories around," i.e., getting rid of the dualistic notions of "mental" and "material," we are able to "recognize" consciousness as what it really is.

Searle strongly believes that despite the fact that consciousness has an ontologically subjective mode of existence, one can make epistemically objective statements about such subjective states: thus if person $A$ tells person $B$ that he has pains in his lower back, this, in an epistemic sense, counts as a "matter of objective fact, not a matter of subjective opinion" (Searle 1998: 45), in spite of the pains themselves only existing as A's subjective experiences. How can we have epistemically objective knowledge of domains that are ontologically subjective? Because, the Searlean realist will claim, the ontologically subjective can become known ("is revealed") to others through the publicly available, intersubjectively shared linguistic code. How, then, does this linguistic code relate to epistemically objective knowledge? In order to accept that such knowledge may be gained, words need to be seen as "standing for" (or being "surrogates" of) things in the external world, and, more generally, it has to be assumed that language is a means of truthfully describing "reality," regardless of its ontological nature. Linguistic statements hence turn out to either match or not match the scientific 
facts, i.e., that which can truly be said of something: the statement " $A$ has pains in his lower back" is only epistemically objective (i.e., can truly be said about $A$ ) if (i) indeed $A$ is in pain, and (ii) the pain is really in the lower back (and not somewhere else). The integrationist takes issue with this approach because it disregards the fact that in some contexts the expert's opinion may clash with the layman's opinion (e.g., concerning the latter's pain), and hence what can "truly be said" about something (and what cannot) requires that one opinion be deemed correct and the other incorrect: dismissing the layman's (verbally expressed) state of mind as unreal because science is able to prove it wrong can, of course, turn out to be for his/her benefit in some cases; such a dismissal, however, hardly does justice to the fact that the layman's opinion might be just as "true" or "real" for him/her as the expert's opinion is for the expert; in other words, both the layman and the expert base their opinions on evidence, and both may have (moments of) doubts regarding whether their opinion is correct or not. To view the scientist, in Searle's words, as stating a "matter of objective fact" as opposed to the layman simply expressing his/her "subjective opinion" is, epistemologically speaking, unsatisfactory because such a view is not in line with the ordinary lives of humans, and therefore itself estranged from reality.

On that score, I would like to draw on a relevant experience reported by a student of mine concerning an undergraduate of the University of Hong Kong. ${ }^{3}$ The latter was going through a very difficult period due to a family member suffering from an incurable disease; this, in turn, caused the student to fall into a depression and to be affected by a constant feeling of impotency in her legs. At the same time, a Japanese series was being shown on TV: one of its protagonists, a young Japanese girl, was suffering from spinocerebellar atrophy, which the student knew could lead to loss of control of one's limbs and, ultimately, to death. The student consulted an online health information site in order to learn more about this particular disease, and found out that her symptoms were very similar to the ones described by various online bloggers commenting on spinocerebellar atrophy. Believing that she was near to death, the student went to see five different doctors, who all diagnosed her as suffering from Generalized Anxiety Disorder, impotency of one's legs being a symptom of this disorder. However, the student doubted the experts' diagnoses, apparently because, in her own words, she "firmly believed that our world was so complicated and things were not simple"; moreover, she thought it "ridiculous that anxiety was related to legs." One of the doctors prescribed her an antidepressant, but because the student had

3 I am grateful to Frankie Yeung Ka Chun for having directed my attention to this particular case. 
learned from the health information site that this medicine could cause addiction she would not take it at first. Finally, the fifth doctor managed to convince her to try the antidepressant; after a few weeks, the feeling of impotent legs was gradually alleviated, and the student accepted that she was really suffering from Generalized Anxiety Disorder.

\section{Integrating signs, experience, and reality}

From an integrational point of view, therefore, what we know about consciousness (or "experience") is never - pace Searle - epistemically objective, precisely because a neurobiological account does not tell us all there is to know in order for such knowledge to be objective. I would like to underline this statement by inviting the reader to think through an imagined (communicational) episode (and its different plot variations): suppose a good friend is looking out of the window into my garden (or yours, as it were) in a way that suggests that her attention is caught by something/somebody, and I ask her what she sees (because I have no view onto my garden at that moment): let us assume she answers "a mouse." How is her utterance to be assessed if I join her and look out of the window as well - and see my hamster instead? Taking a decontextualized and depersonalized perspective, the Searlean realist will argue that my friend's visual experience was incorrect - not in line with the facts - based on the answer she gave me. Her conscious experience and the world "as it is" are not congruent, if she "really" thinks that my hamster in the garden is a mouse. But suppose I know from personal experience that this friend of mine calls all rodents "mouse": thus, I may sense that my friend is actually referring to my hamster before I reach the window (precisely because on previous occasions she has referred to my hamster as "mouse") - or I may not even go to the window to see for myself but rush directly to the garden in order to catch my hamster before the neighbor's cat finds it. Alternatively, my friend may realize that she was mistaken before I am able to protest (i.e., before I have reached the window and told her that she is mistaken), and she may correct herself: "I mean a hamster, of course!" At any rate, the situations imagined here involve different orders of experience and knowledge (e.g., Harris 2009a: 166), namely, my friend perceiving what she perceives, as opposed to her reporting to me what she perceives, as well as my interpretation of her report. All of these activities require a very different set of integrations. Taking my friend's answer as evidence of her visual experience, excludes ab initio any creative (or playful) aspect of language use, e.g., if my friend wanted to tease me because she knows that I am sensitive when it comes to calling my hamster a "mouse." There is no hearerindependent way of knowing my friend's intention behind her answer: asking her 
is, of course, a viable course of action for me to take, but then we are already at one remove from the first-order experience "in its original state" (i.e., my friend's "explanation" involves integrational activities on both her and my part which align with the new situation). As the integrationist would point out to the Searlean realist, the facts as first-order experiences lie outside the reach of epistemic objectivity (which is what any science of the mind is ultimately after). No neurobiological account of my friend's visual experience could possibly solve the mystery as to what my friend "really" saw and why she said that what she saw was a mouse. As Roy Harris aptly remarks in After Epistemology:

\begin{abstract}
The integrationist approach to the philosophical "problem of perception" regards it as arising from a failure to see where the linguistic source of the muddle lies. Once again, it arises from mistaken assumptions about language in the present and the past, and not from mysterious neurophysiological processes still awaiting investigation in the future. If we reject the naive reocentric semantics that dominated Western thinking for so long, there is no longer any room for general problems of the form "Is what I perceive to be an $x$ 'really' an $x$ ?" This is not to deny that people can be mistaken in individual instances, but to point out that it is nonsensical to worry about whether grass "really is" grass, water "really is" water, and so on. Grass, water, etc. are not Adamic names. They do not somehow reflect the "true nature" of anything, nor is there any sense in which that is - or should be - their semantic function. (Harris 2009a: 154)
\end{abstract}

Hence, whether my friend's answer counts as a joke, or maybe as an ironic remark, has to do with who interprets the utterance in what circumstance, i.e., how a particular individual integrates past experience with the present situation, thereby anticipating possible future situations. Postulating, as Searle (1969) does, that communicative behavior is governed by constitutive rules shared by the members of a linguistic community is not knowledge that suffices in concrete communicational episodes involving concrete people: thus, the formulation " $\mathrm{X}$ counts as (has the social function of) Y, in context C" (Searle 1998: 153) only works on an abstract - a depersonalized and decontextualized - level. That is, the knowledge involved in my interpreting my friend's answer as equivalent to, say, "if I were you, I'd better run and save your hamster before a cat kills it," because uttered by her in a very specific, familiar manner, and with that certain look on her face, etc., cannot be captured in any linguistic formula laying claim to general validity (e.g., Harris 1990: 130). Please note that I am not thinking here of a situation analogous to the one we typically find in secret agent stories: I am not thinking of a situation in which I am waiting for my friend to give me a signal, such as uttering a code name (e.g., "mouse"), which initiates the secret operation. In the imagined scenario above, I may simply not have been expecting my hamster to be running free in the garden because I was sure the animal was in its cage inside the house. 
The realness of experience - in the sense that the experience of something is real if that something "really" is/was there (its conditions of satisfaction), and if that something causes the very experience that has these conditions of satisfaction - is hence a bogus problem conjured up by the Searlean realist, who cannot accept that after all subjectivity is not that unproblematic as a domain of scientific investigation. What is more, "truth" is not automatically an issue at every level of experience: it is an issue, for instance, if I ask my friend (from a location where I can't see out of the window) whether she is sure that what is running around in my garden "really is" a mouse, thus forcing her to recontextualize her previous visual experience; conversely, she may do so herself as when she is rubbing her eyes and looking out again because she can't believe that there is a hamster running free in my garden (her guess being that it surely must be some sort of a "mouse"). Taking Searle's external realism as one's point of orientation, compels one to distinguish what is real from what isn't: thus, Searle tells us, an intentional conscious state can fail altogether, because there is no object there that the mental state could be about: a child may believe in Santa Claus, even though Santa Claus doesn't exist. The child's belief, according to Searle (1998: 99), fails to have a "mind-to-world direction of fit," which is the criterion adopted by science to discriminate between the real and the unreal, the normal and the aberrant, the factual and the fictional. Reality and consciousness must match for the Searlean realist: if I recollect a certain event (rather than imagining it), not only must this event really have happened, but that very event must cause the memory that has those conditions of satisfaction: thus, cognitive states have, in Searle's terminology, a "world-to-mind direction of causation." But that surely does not do justice to the phenomenon of memory: did the event as I am presently recalling it "really" take place the way I am recalling it? How is one to find out? By thinking hard enough? Remembering something is always to abstract an episode from an open-ended continuum of personal experiences, events and activities. In this perspective, memory and reality can thus no longer be claimed to match - or not to match - as there is no objective court of appeal to turn to. What is of importance here is, as Harris (2008: 145) points out, that the primary function of such verbs as remember or imagine is "nothing other than to integrate two kinds of experience that we all have: experience of an "inner" world and experience of an "outer" world." Hence, the integrationist does not wish to deny that there is a connection between what "I recollect seeing" and "what I saw." As Harris (2008: 247) states, "[i]t seems to me important - I would go further and say essential to our humanity - that we have available a language in which verbs like imagine, dream and remember can take the same predicates as see, hear and perceive." The relation between how things really happened and remembering how things really happened (and its subsequent verbal report of it) is certainly of 
consequence in many situations of everyday life (classic examples being our attempt at reconstructing where we might have put the car-keys, or asking our youngest child who of the two older siblings started the fight), even though, again, we must distinguish between our witnessing an event, our remembering it and our reporting it to, or respectively discussing it with, others: all of these require different integrational activities in completely novel situations.

\section{Two views on proper names}

How does the Searlean realist view cognitive mental states, such as beliefs and knowledge, and how do they relate to the real world? The phenomenon of proper names should serve as a case in point: in orthodox philosophical thinking, names "stand for" their (real-world) referents, and it comes as no surprise to find that John Searle, adopting the reocentric "stand-for" idiom in respect to proper names (Searle 1998: 98), clings to what Harris has termed "the myth of reference" (Harris 2009b: 47-54): my knowledge (or belief) of who a name refers to must either have, in Searlean terms, a "mind-to-world direction of fit," or fail to have one, and respectively a "world-to-mind direction of causation." Once the (correct) link between name and referent has been registered by my mind, the reasoning goes, it is "potentially available" when needed, and therefore always present and represented in my mind. However, from an integrational point of view, knowing a name involves (and is the same as) its contextualization, i.e., knowledge is never contextless (Harris 2009a: 99). This position contrasts sharply with a Searlean epistemology, according to which people need to have a firm grasp of ("know") reality in order to be functional members of any macro-social group, which in turn presupposes knowledge of stable, correct name-referent relations - a knowledge which antecedes actual usage. I would like to contest this view and substitute for it an integrational account of reference: for this, I will rely on two personal experiences of mine as a Westerner in Hong Kong.

The first episode concerns my encounter with a local taxi driver, who, like many of his colleagues, only has minimal knowledge of English: I once asked him to take me to a local (i.e., Chinese-medium) primary school, the English name of which is Rosary Hill. I tell the driver the name of the street where Rosary Hill School is located: Stubbs Road. I can't recall the number, however. So the driver takes me to a school named Bradbury, which is run by the English Schools Foundation (fully English-medium, partly government-subsidized schools popular with both Westerners and Chinese). I recognize the surroundings, as I have already been to Rosary Hill, and direct the driver to the street that leads up to Rosary Hill School. As it turns out, Bradbury School is located on $43 c$ Stubbs 
Road, while Rosary Hill is on $41 b$ Stubbs Road. The driver only knows the Chinese name of Rosary Hill (I know so because, on arriving there, I asked him to tell me its local name). Knowing the Chinese names of some buildings and streets is vital in Hong Kong, as many taxi drivers aren’t familiar with its English counterparts. Why did the driver take me to Bradbury? Maybe because he heard Bradbury when I said Rosary, or because he reanalyzed Rosary as actually, or at least potentially, being Bradbury. There are hardly any Westerners at Rosary Hill, especially not children with two Western parents (as in my case). Western children usually attend either international schools or ESF schools, Chinese being only a foreign language subject (if at all). How would the Searlean realist make sense of this episode? He/she would certainly insist that the interactants' respective beliefs (or knowledge) were in line with reality. My belief was about Rosary Hill School, the driver's about Bradbury School. We failed to "synchronize” our knowledge due to different linguistic backgrounds. However, if this kind of knowledge is no use in concrete communicational encounters, it is little consolation to claim that both interactants grasped reality, and had I known the Chinese name of Rosary Hill School the confusion would not have arisen in the first place. I do not think that the crucial issue here has to do with "languages": in fact, I have been told that Westerners who are fluent speakers of Cantonese cannot always make themselves understood to the locals, even though their Cantonese pronunciation is, in their view, faultless; one possible interpretation of this is that the locals simply do not expect a Westerner to address them in Cantonese, just as they probably do not expect a Western child to attend a local school, especially not if there is a fully English-medium school in the very same street. Thus, even if the taxi driver had been acquainted with the English name Rosary Hill (and even if he had heard it as Rosary Hill when I told him my destination, without specifying the street number), he may still have taken me to Bradbury School first. This is so because names do not refer to anything independently of contexts.

The second Hong Kong anecdote equally concerns a confusion of names. As my wife and I were not entirely happy with our previous apartment (mainly due to the size of the flat), we happened to seek advice at a real estate agency that is located very close to where I work. We told the agent that we were staying in University Heights (the name of the building we were living in the time), and that we were interested in more spacious apartments than our current one. The agent, a Hong Kong Chinese, showed us several flats in the neighborhood, where many Westerners reside because of the convenient location: all of these streets, in fact, are close to the financial district called Central. What struck me about the apartments we were shown was that even though they were more expensive than ours (because slightly bigger), they were in rather bad shape. I pointed out several times to the agent that our flat was in a much better condition, and the rent 
lower. Moreover, I kept telling her that we had sea-view (which those we were shown did not), fewer buildings surrounding us, and more greenery. At one time, we are walking on Kotewall Road, and the agent turns to me and says that now we are very close to University Heights, where we live (and points to a high-rise building nearby). I am perplexed, and explain to her that we do not live there, but in University Heights, located on Pokfield Road (in another district). As it turns out, there are two University Heights in that area, with different Cantonese names. Now the agent suddenly understood why our rent was lower (because our building is a bit farther away from Central District). All the time we were together, the agent just simply did not think of “our” University Heights as a possibility. Since I was working at the University of Hong Kong, very close to her office, and since we showed interest in buildings in the area where her office is located, the agent simply assumed that our University Heights was in fact the one closer to the University, the one in Kotewall Road. In turn, it never did cross my mind that there could be two residential buildings named University Heights. All that time, the agent must have been thinking that I was giving her information which did not correspond to the facts as she knew them, i.e., concerning the rent, the surroundings, the building and flat we were living in, and its size. I, on the other hand, thought the agent insensitive because she only showed us old flats that in my opinion were less nice than ours.

From an integrational point of view, reality is a second-order construct (a macrosocial abstraction), which corresponds to no-one's concrete personal experience with the world. When invoking reality (as an independent ontology), individuals draw on their personal experience with reality, with which the abstraction is made to match. Reality is "macrosocial" insofar as it is a label used by people in multiple ways as part of social interactions; second, what counts as "real" or as part of the "real world" will differ depending on the culture, religion, technology, the time period, etc. Lastly, the individual's experience of "reality" is greatly influenced by culture-specific and social factors. Thus, the Hong Kong agent's idea of "reality" was in conformity with the facts available to her: a Westerner, employed by the University of Hong Kong, who lives at University Heights, which, even though conveniently located (as she thinks we live in Kotewall Road), is too small for a family, which is why he is looking for a bigger apartment, equally conveniently located. The agent could not help integrating the "straightforward" pieces of information she had received from me with her own presuppositions (about me), her experience with Western clients, and the circumstances in which we had met. She could not help it because she is human. This, however, should not be taken to mean that another real estate agent would have made the same presuppositions: this is so because no two real estate agents have the same (communicational) experience. The fact that I have been discussing two episodes 
involving some sort of "misunderstanding" should not tempt us to assume that in "normal" cases experience and reality either match or do not match. I am advocating here that the two Hong Kong episodes are actually just two extreme cases of what happens all the time when we are using names in communication (e.g., Harris and Hutton 2007: 208). Viewed in this way, the two Hong Kong episodes are not necessarily communicational "failures": they rather illustrate that each of us segments reality according to his/her subjective knowledge of reality in concrete (often unpredictable) contexts. Hence, it would be misguided to conceive of the two episodes as involving types of people, i.e., the present author as a representative of the Western expat in Hong Kong, as opposed to the taxi driver and the real estate agent as merely representatives of local professionals (of a particular branch). ${ }^{4}$ The skeptic could, at this point, accuse me of merely "reading into" what actually happened in the two (communicational) episodes, and expose me for preferring speculation to neuroscientific investigation. However, as the "mouse-or-hamster" case as well as the two Hong Kong episodes show, my introspections are based on (recollections of) personal experiences with other people (friends as well as strangers), and imagined (but possible) situations: they are as real as it can get, in the sense that their realness is not lesser in degree than if I had tape- (or video-) recorded the episodes. The facts, as far as my examples discussed are concerned, do not need recording: when it comes to my encounter with the taxi driver, for instance, I know that I told him to take me to Rosary Hill School; moreover, I have no doubts that I knew well which school I was talking about when I directed the driver to take me to Rosary Hill, and I also know for sure that the driver first took me to Bradbury School instead. These are the "facts" and any Westerner could imagine being in the "same" situation. There is no need to enter anybody's mind (or brain) in order to state that mutual understanding between the driver and me was not achieved until the driver realized that I did not mean Bradbury School. ${ }^{5}$ Hence I felt confident that the driver had "understood" me long before we reached Stubbs Road (because while driving he was indeed taking the roads I expected him to take in order to reach Rosary Hill), and he, most likely, also thought he had "understood" me. What the driver thought I had said,

4 I think that one's personality plays an important role in communication. In fact, some Hong Kong taxi drivers are more at ease with Westerners and will show surprising linguistic skills, as I and my family were able to witness when an elderly driver, before we got off, addressed us in very good German (he had been learning German for many years) because he had recognized our conversation in Swiss-German as being "German."

5 However, we must not make the mistake of concluding that this "final" understanding was of a surrogational nature: understanding is always an integrational (non-discrete) process, but we - the lay speakers - tend to overlook that fact, because language allows us to say things like "Now he has understood!" I am grateful to Michael Toolan for making this point clear to me. 
and how exactly this relates to his taking me to the other school is a matter of personal interpretation (and hence lies beyond scientific investigation): perhaps the driver heard Bradbury (not Rosary), or perhaps he indeed heard Rosary but thought that actually I meant Bradbury. ${ }^{6}$ I have simply offered the reader my view on this, and I think it is a plausible explanation. What this means, crucially, is that the taxi driver may have reflected on the episode as well (and discussed it with his colleagues), and, if so, may have come up with his own account of "what happened" and "why." The latter account, according to the integrationist, is not in any way inferior to mine; it is, however, an account by someone with a very different background (professional, cultural, experiential, etc.).

An obvious advantage of working with names as a means of showing how language relates - or, as it were, does not relate - to consciousness is that referents can in many cases be identified on the spot, e.g., when informants point directly to the building or street they are talking about (or at least in their direction). Hence, "understanding," in this respect, is comparable to somebody passing the salt when being asked "to pass the salt" (note that in the latter example a pointing gesture often accompanies the request); however, it is unlike the "understanding” attributed to somebody who answers "yes, of course!" on being asked "do you understand what I mean?"

\section{The integrational nature of language and discourse}

A Searlean linguistics conceives of language as a surrogate for reality on the one hand but also as thought-determining on the other. In this sense, the question to what extent folk psychological (as well as folk linguistic) terminology adequately reflects the latest scientific insights becomes a crucial one for the Searlean realist. But what about the integrationist? Does it make sense at all for integrationists to use these very terms, given that they are, as Talbot Taylor (2002: 101) remarks, "infected with the language myth"? If the integrationist holds that such concepts

6 My experiences with taxi drivers include many other episodes in which the driver heard something quite different from what I said: for instance, recently I told a driver that I had to stop at a bank to withdraw money and that there was an $H S B C$ branch (of which I am a customer) very close by. The driver took me to another bank, $N C B$, instead (which was also in the same neighborhood, but required a detour, making me lose about ten minutes because to get there we had to drive around several blocks), in spite of my showing him which street he had to take (which was the "wrong" street in his view, as he didn't know there was an HSBC in the neighborhood). 
as understanding, meaning, sign, reference are ill-conceived within orthodox psychology and linguistics, shouldn't he/she strive to avoid them at all costs in professional contexts, and replace them with better ones? Shouldn't the integrationist - like the eliminativist - ban folk psychological terminology on the grounds that there is nothing scientifically real that these terms refer to? Taylor (2002: 101) ponders about precisely these questions, and asks himself:

What should be the integrational linguist's position on folk psychology and folk linguistics? Specifically, should all, some, or none of the constitutive concepts be retained in the integrational study of language and communication? Should one of the integrationist's goals be to show what meaning, understanding, reference, belief, etc., really are - i.e., properly seen within an integrationist approach that has freed itself from the influence of the Language Myth? Or, should the goal be to replace these conceptual and terminological legacies of the Language Myth (and perhaps other Western cultural myths) with terms and concepts that (a) are motivated directly by the integrational approach and (b) do not "carry with them" the conceptual baggage of the Language Myth? To put it bluntly: Should the integrationist aim to explain what it is to mean, to understand, to believe, to refer, to be a sign of, etc? Or should this not be one of the integrationist's aims, on the grounds that those terms are too infected by the Language Myth? (Taylor 2002: 101)

The reader will have noticed that I have made constant use of folk psychological terms throughout this text (e.g. refer, believe, presuppose, perceive, mean, intend, consciousness, mind, experience). Frankly speaking, I would not know how to write such a text in the first place without having recourse to these (and many other) words of which I do not believe they can be explained scientifically (in the "realist" sense of the term). Harris has dealt with the question of the validity of folk psychological terms in a chapter of Mindboggling (Harris 2008); he assumes the naïve reader's perspective and asks himself the following with reference to terms denoting volitional mental states:

... does not all talk of acts of the will, of decisions, personal commitment, my determination to carry out certain courses of action, etc. merely set up a linguistic smokescreen behind which the "real" mechanisms involved are hidden? Should not this kind of talk therefore be banished from any sanitized mindspeak, or at least be disregarded? (Harris 2008: 28)

Harris concludes, however, that

It is ... essential that we retain a mindspeak that allows us to describe such experiences as trying to give up smoking, or hesitating about whether to hand in our resignation, and hundreds of others where prima facie the will is involved. For there simply is no other vocabulary that is currently available for such purposes. The option is not between retaining the traditional language of mental acts and substituting for it a more accurate mode of 
description. The alternatives are retaining the traditional language of mental acts or saying nothing at all, i.e. refusing to discuss those aspects of our human experience. (Harris 2008: 29)

Integrationists, therefore, radically differ from realists (of the Searlean type) in their respective philosophies of language, insofar as, even though neither have a problem with folk terminology per se, the latter are preoccupied with how ordinary language penetrates the language of science. This is so because, unlike the integrationist, the Searlean realist insists on an isomorphic relationship between scientific language and reality, which requires that terms shared by both laypeople and scientists need semantic "updating" for the purpose of professional scientific communication. For the integrationist, however, the functionality of terms is an "integrational" issue - not a "reocentric" one: to use a word is to contextualize it, irrespective of the subject matter. This, in turn, is tantamount to a denial of "code-given" truths.

The mistake of a Searlean realist philosophy lies in simply presupposing that there is a "genuine phenomenon" (e.g., the phenomenon of consciousness), the existence of which is, in principle, independent of language, and to assume that this observer-independent realm of "nature" can be captured truthfully (or will be eventually) by means of the language of science, where words possess accurate (i.e., scientifically "up-to-date") meanings. In a post-Cartesian age, Searle informs us, the word consciousness is no longer incompatible with such words as matter or physical: consciousness is now a "different" word in the new language of biological naturalism - a code in which mind and brain are no longer treated as mutually exclusive terms: "That is our account of the metaphysical relations between consciousness and the brain. Nowhere do we even raise the questions of dualism and materialism. They have simply become obsolete categories. We have thus 'naturalized' consciousness, and indeed, my label for this view is 'biological naturalism'” (Searle 1998: 53-54).

The integrationist, in turn, does not feel the need to "naturalize" (the word) consciousness, and, by doing so, to treat everyday human experience as alienated from scientific observation; in fact, I still find it useful to discriminate between the mental and the physical (after all, I do not consider my mind - pace Searle on a par with my digestion); neither do I feel any qualms whatsoever about using the attribute spiritual, or talking about my "conscience," even though I would perhaps refrain from using them in certain academic contexts - not for reasons having to do with "ontology" in a Searlean sense, but because of the circumstantial parameters constraining communication (Harris 1998: 29). In a Searlean utopia, ordinary language and scientific language can be neatly separated, as if science existed in a communicational vacuum. Ironically, such a view reveals a 
naïve (dualistic) notion of the layman-turned-scientist as speaking/thinking qua scientist, as opposed to the scientist-turned-layman as speaking/thinking qua layman. To come back to Talbot Taylor's point (as quoted above): it seems to me that simply by redefining terms "infected with the Language Myth" (or by coining purely "integrational” ones), one cannot - pace Searle - free oneself (once and for all) from previous macrosocial discourses: realizing this is a big step towards self-knowledge - and towards understanding what it is to "integrate." Hence, when theorizing communication and how it "really" works, the integrationist does not try to hide the fact that people may well experience language in ways that run counter to what the former thinks is "really" going on when two (or more) persons interact: this would amount to a denial of the individual's right to his own linguistic experience (and the freedom to express that experience). What a Searlean realism fails to take into account is that the past cannot be accessed but through the present, nor can macrosocially embedded activities ever be autonomous.

\section{Against a "semantics for robots"}

It has been argued here that Searlean realism disregards the human component altogether, chiefly because its foundations lie in the "Language Myth" (Harris 1981). It is, therefore, not rooted in reality. Searle's vision of a science of consciousness is underpinned by, to use a Harrisean phrase borrowed from The Language Machine, “a semantics for robots, not human beings” (Harris 1987: 159), even though Searle himself (1998: 54) emphasizes that in biological naturalism the mode of explanation of the existence of mental phenomena is biological (and not computational, or linguistic); still, it is ultimately language (conceived of as a fixed-code) that enables the biological naturalist to identify underlying conscious states - to be, ideally, reproduced in the laboratory. As the integrationist would argue, human beings are integrating beings, and conceiving of contextuallyembedded experiences as "manifestations of" type experiences reduces the person to a type of person.

Hence, whenever I ask a taxi driver to take me to Rosary Hill School it sure feels like I am in the "same" situation again; however, it never is, for my integrational proficiency, i.e., "the whole range of knowledge, abilities and experience that [I] can bring to bear on the communication situation" (Harris 2009b: 70), is never the same. How I go about avoiding ending up at the wrong school depends on many factors (both integration and circumstances never being fully controllable): it will depend, for instance, on the taxi driver's reaction (sometimes those with very little command of English have to call the headquarters in order for the 
Western customer to tell the English name of the address to an English-speaking employee, who will then translate it into Cantonese to the driver), the route the driver chooses to take (which also depends on where one takes the taxi), and whether the Western client is familiar with that route. The same is true when it comes to the taxi driver who took me to Rosary Hill School: having had the experience with me does not guarantee that, should the driver have another Western client wishing to go to Rosary Hill, everything will go "smoothly."

Positing the existence of an independently given world, in which each thing has its proper place and its "proper" name, has very little to do - if anything with how individuals concretely experience first-order reality. Searle's science of consciousness searches for the truth by relying on neuroscientific evidence as well as pragmatics: integrationists, in turn, do not regard lay accounts of the mind and its workings as unreliable (they take them seriously, however reocentric they may be), and prefer to replace "truth" with "integration" (as the only first-order experiential universal), thereby acknowledging the "constructive, i.e. creative, role of the individual in the sign-making process" (Harris 2009b: 66).

\section{References}

Harris, Roy. 1981. The language myth. London: Duckworth.

Harris, Roy. 1987. The language machine. Ithaca: Cornell University Press.

Harris, Roy. 1990. Making sense of communicative competence. In Nigel Love (ed.). The

foundations of linguistic theory: Selected writings of Roy Harris, 112-135. London \& New

York: Routledge.

Harris, Roy. 1996. Signs, language, and communication. London \& New York: Routledge.

Harris, Roy. 1998. Introduction to integrational linguistics. Oxford: Pergamon Press.

Harris, Roy. 2004a. Integrationism, language, mind and the world. Language Sciences 26(6).

727-739.

Harris, Roy. 2004b. The linguistics of history. Edinburgh: Edinburgh University Press.

Harris, Roy. 2008. Mindboggling. Luton: Pantaneto Press.

Harris, Roy. 2009a. After epistemology. Gamlingay: Bright Pen.

Harris, Roy. 2009b. Integrationist notes and papers. 2006-2008. Gamlingay: Bright Pen.

Harris, Roy \& Christopher Hutton. 2007. Definition in theory and practice: Language, lexicography, and the law. London: Continuum.

Love, Nigel. 1999. Searle on language. Language \& Communication 19(1). 9-25.

Searle, John. 1969. Speech acts: An essay in the philosophy of language. Cambridge: Cambridge University Press.

Searle, John. 1998. Mind, language, and society: Philosophy in the real world. New York: Basic. Searle, John. 2002. Consciousness and language. Cambridge: Cambridge University Press.

Taylor, Talbot. 2002. Folk psychology and the language myth: What would the integrationist say? In Roy Harris (ed.). The language myth in Western culture, 100-111. London: Curzon.

Toolan, Michael. 1996. Total speech: An integrational linguistic approach to language. Durham \& London: Duke University Press. 


\section{Bionote}

Adrian Pable (b. 1971) is an assistant professor at the University of Hong Kong 〈apable@hku.hk〉. His research interests include integrational linguistics, sociolinguistics, dialectology, and historical linguistics. His publications include $I$ nomi di luogo di Bellinzona. Aspetti sociolinguistici e di costume onomastico nella Città dei Castelli (2000); and The construction of a period dialect: The language of Arthur Miller's The Crucible and its sources (2007) and Signs, meaning, and experience: Integrationism and semiotics (with C. Hutton, forthcoming). 